This is a preprint version of the following chapter (version 2-2017):

Okada, B. M., \& Slevc, L. R. (in press). Musical training: Contributions to executive function. In M. Bunting, J. Novick, M. Dougherty, \& R. W. Engle (Eds.), An Integrative Approach to Cognitive and Working Memory Training: Perspectives from Psychology, Neuroscience, and Human Development. New York, NY: Oxford University Press.

\title{
Musical Training: Contributions to Executive Function
}

Brooke M. Okada and L. Robert Slevc

University of Maryland, College Park

Imagine you are the first violinist in a string quartet. Each time you and your colleagues rehearse, you engage multiple cognitive processes. While playing, you must continuously listen and attend to multiple auditory streams of music (i.e., your own playing as well as the music from your violinist, violist, and cellist) to coordinate your group's sound. You must also constantly adjust your tempo, volume, and timbre to match that of your group to highlight certain melodies and coordinate nuances within the music. Simultaneously, you are also reading your music filled with notes and extra markings, and these items must be held in mind until played. These processes likely require a variety of cognitive processes, such as the cognitive flexibility to switch between auditory streams and the ability to update working memory when reading from the score. Both are part of a larger set of cognitive processes termed executive functions (EFs).

EFs, also known as cognitive control, are a set of top-down processes involved in the planning and regulation of cognition and behavior (e.g., Diamond, 2013; Diamond \& Ling, 2017; Miyake \& Friedman, 2012). Most models of EF posit three core related but separable components: inhibitory control, cognitive flexibility (also known as switching or shifting), and working memory updating (Diamond, 2013; Lehto, Juujärvi, Kooistra, \& Pulkkinen, 2003; Logue \& Gould, 2014; Miyake et al., 2000; Miyake \& Friedman, 2012). Inhibitory control requires the control of one's thoughts or behavior to override a prepotent response. Cognitive flexibility requires one to change perspectives or switch between task demands. Lastly, working memory updating requires one to maintain, add, and delete items from memory. These EFs develop through adolescence and can be improved with practice (Diamond, Barnett, Thomas, \& Munro, 2007; for a review, see Diamond, 2013).

Because EFs are such a critical aspect of cognition (e.g., EFs are important predictors of success in school and mental health; Diamond, 2013), there is considerable interest in predictors of EF abilities and how one might improve EFs (see Diamond \& Ling, 2017). Accordingly, a variety of EF training paradigms have been developed (e.g., Chein \& Morrison, 2010; Jaeggi, Buschkuehl, Jonides, \& Perrig, 2008), although it is debatable whether these programs lead to improvements extending beyond the specific EF skill trained (particularly regarding fluid intelligence; e.g., Au et al., 2015; Dougherty, Hamovitz, \& Tidwell, 2015; Owen et al., 2010). However, it is clear that specific EF processes can be improved from even relatively short experiences 
(Harrison et al., 2013). That is, there is good evidence for process-specific "near transfer," where improvements reflect the specific abilities taxed by a training task. Thus, regular engagement in tasks that rely on specific EF abilities could benefit those specific aspects of EF.

While carefully controlled EF training paradigms provide essential tools to understand cognitive training and transfer effects, one limitation with many of these paradigms is that the training tasks are not particularly interesting or rewarding on their own. Even if intense training on, for example, a dual N-back task can lead to improvements in EFs or other cognitive abilities (Jaeggi et al., 2008), it seems unlikely that many people would like to spend hours practicing their N-back skills. Some informal evidence for this comes from the fact that most cognitive training studies pay participants relatively well, yet still have relatively high rates of attrition. For example, Redick et al. (2013) reported an approximately $20 \%$ attrition rate despite paying $\$ 352$ to participants who completed all parts of the study. Many commercial (and noncommercial) cognitive training programs address this problem of engagement by making training tasks game-like (e.g., the web-based packages Cogmed $^{\circledR}$ and Lumosity ${ }^{\circledR}$ ). However, an alternative possibility is to target other tasks that draw heavily on specific EF abilities but that have their own intrinsic rewards. One such complex, yet commonly pursued activity is music training (e.g., Hannon \& Trainor, 2007; Moreno \& Farzan, 2015; Slevc \& Okada, 2015).

The idea that musical experience might lead to benefits to cognitive processes (as well as social outcomes) is both longstanding and widely held. For example, Jose Antonio Abreu, the founder of El Sistema (a music program targeting children in need) has said:

"Children engaged in the programme [El Sistema] attain above-average results in school and show a tremendous capacity for collective community action. The orchestra and the choirs, the heart of the programme, help create a sense of solidarity. Involvement becomes a weapon against poverty and inequality, violence and drug abuse." (Burton-Hill, 2012, p. 1)

Note that Abreu's suggestion is that active engagement in a music program, not passive exposure to music, will affect cognitive processes. Although passive music listening can affect a range of behaviors, including shopping behavior (Andersson, Kristensson, Wästlund, \& Gustafsson, 2012; Milliman, 1982), worker productivity and attention (Shih, Huang, \& Chiang, 2012), and exercise (Karageorghis \& Priest, 2012), there is only limited evidence for effects of passive musical exposure on cognitive functioning (i.e., there is little evidence for the "Mozart Effect"; Pietschnig, Voracek, \& Formann, 2010). Instead, cognitive effects of passive musical exposure likely reflect underlying effects on emotion and arousal rather than transfer effects per se (Thompson, Schellenberg, \& Husain, 2001; Slevc \& Okada, 2014).

In contrast, there is growing evidence that active music training is associated with a variety of nonmusical cognitive abilities (e.g., the special edition of Music Perception on "Music Training and Nonmusical Abilities" [Schellenberg \& Winner, 2011]). As mentioned above, the idea that music training might produce collateral benefits for EFs is particularly interesting in part because many people find learning to play an 
instrument (or sing) intrinsically enjoyable in contrast to computerized EF training paradigms, for example. Another benefit of music training as an EF training paradigm is that it naturally involves multiple cognitive processes since it is a multifaceted activity. Playing an instrument requires that one learn to read music, translate printed notes into planned motor sequences, acquire fine motor coordination, and hold many notes and pieces in memory (Peretz \& Zatorre, 2005). Indeed, Diamond (2014; Diamond \& Ling, 2017) has posited that activities requiring progressively challenging EF skills, and in which individuals find enjoyment and emotional investment, should be the best at improving EFs.

In addition, there is good reason to think that music training can lead to both neural and cognitive changes. Much of the evidence for this focuses on consequences for motor and auditory processing. For example, compared to a matched control group, those who took 15 months of private keyboard lessons showed structural brain changes (based on deformation-based morphometry) in motor and auditory areas involved in learning music (Hyde et al., 2009). Similarly, professional keyboard players have greater gray matter density in motor areas (left Heschl's gyrus and left inferior frontal gyrus) in comparison to amateur musicians and nonmusicians (Gaser \& Schlaug, 2003). In addition to structural brain changes, music training has also been associated with behavioral advantages in a wide range of cognitive processes. Music lessons have been found to correlate with multiple cognitive processes including, but not limited to: verbal memory (Chan, Ho, \& Cheung, 1998; Ho, Cheung, \& Chan, 2003; Jakobson, Cuddy, \& Kilgour, 2003; Jakobson, Lewycky, Kilgour, \& Stoesz, 2008); reading ability (Lamb \& Gregory, 1993; Butzlaff, 2000); mathematical ability (Vaughn, 2000); spatial skills (Bilhartz, Bruhn, \& Olson, 2000); IQ and academic ability (Schellenberg, 2006, but see Sala \& Gobet, 2017; Schellenberg \& Moreno, 2009); selective auditory attention (Strait \& Kraus, 2011); auditory working memory (Pallesen et al., 2010); and processing speed (Bugos \& Mostafa, 2011).

Of particular interest here is whether musical experience can specifically affect EF abilities. There is at least some evidence for EF-relevant neural effects of music training. For example, playing an instrument is related to an increased rate of cortical thickness maturation not only in motor areas recruited for planning and producing movement, but also in the dorsolateral prefrontal cortex and orbitofrontal cortex, areas often involved in executive functioning (Hudziak et al., 2014). However, effects of musical experience on EF abilities are only predicted for those aspects of EF on which music training relies (see Principle \#2 in Diamond \& Ling, 2017). Thus, a first step to understand the relationship of music training and EFs is to consider how music training draws on EF abilities. Below, we detail evidence that music processing involves and taxes different aspects of EF as well as correlational evidence that music training is associated with advantages in EF abilities. We then describe the small, but growing, literature examining the effects of longitudinal music training programs on EF abilities.

\section{Musical Training and Cognitive Flexibility}

Music is often played in ensembles (e.g., symphonic orchestras, string quartets, or choirs), which requires that musicians play in coordination with each other (Palmer, 2013). Such coordination requires performers to switch flexibly between multiple 
auditory streams (Loehr, Kourtis, Vesper, Sebanz, \& Knoblich, 2013) and to adjust to other members of the group (e.g., Loehr \& Palmer, 2011; Moore \& Chen, 2010). This may result in relatively general advantages in cognitive flexibility; indeed, musicians outperform nonmusicians on the Trail-Making Test (a standard switching task; HannaPladdy \& MacKay, 2011; see also Bugos, Perlstein, McCrae, Brophy, \& Bedenbaugh, 2007) and in cued task-switching (Moradzadeh, Blumenthal, \& Wiseheart, 2015). Musically trained children also show greater BOLD (blood oxygenation level dependent) responses in a task-switching paradigm (to bivalent versus univalent stimuli) in bilateral ventrolateral prefrontal cortex and supplementary motor area (Zuk, Benjamin, Kenyon, \& Gaab, 2014), which are regions linked to executive functioning (Nachev, Kennard, \& Husain, 2008; Nee et al., 2013).

\section{Musical Training and Inhibitory Control}

Adjusting one's own playing to that of other performers not only requires the shifting of attention, but also exercising inhibitory control to monitor for conflict and control one's own performance (Jentzsch, Mkrtchian, \& Kansal, 2014; Palmer, 2013). In addition, listening to or tapping complex polyrhythms (e.g., tapping a main meter with one hand and a counter meter with the other) also requires inhibitory control; for example, tapping " 4 against 3" is associated with activation in Broadmann Area 47 and the anterior cingulate cortex (ACC) (Vuust, Roepstorff, Wallentin, Mouridsen, \& Østergaard, 2006; Vuust, Wallentin, Mouridsen, Østergaard, \& Roepstorff, 2011). Because the ACC is associated with aspects of inhibitory control (particularly with conflict monitoring; Botvinick, Braver, Barch, Carter, \& Cohen, 2001), polyrhythmic processing likely involves inhibitory control processes. Thus, music training may lead to more general advantages in inhibitory control. Indeed, adult musicians show smaller interference effects in both a pitch-based auditory Stroop task (where the words "high" or "low" are sung in either a high or low pitch) and in a visual Simon Arrows task (where left- or right-pointing arrows appear on the left or right side of the screen) (Bialystok \& DePape, 2009). Musicians have also been shown to outperform nonmusicians on a stop-signal task (Strait, Kraus, Parbery-Clark, Ashley, 2010; see also Moreno, Wodniecka, Tays, Alain, \& Bialystok, 2014), suggesting an advantage in motor, as well as cognitive, inhibition.

\section{Musical Training and Working Memory Updating}

Sight-reading music, or playing unpracticed from a score, requires looking ahead in the music to prepare one's performance, and good sight-readers typically look about four notes ahead of where they are playing (Furneaux \& Land, 1999; cf. Drake \& Palmer, 2000; Goolsby, 1994). Thus, sight-readers are constantly updating the contents of working memory (WM): they must keep in mind which notes are being played and which are yet-to-be played. Correspondingly, sight-reading ability is related to nonmusical measures of WM capacity, as indexed by an average of scores for operation span, reading span, rotation span, and matrix span (Meinz \& Hambrick, 2010). In addition, musicians outperform nonmusicians on N-back tasks (Oechslin, Van De Ville, Lazeyras, Hauert, \& James, 2013; Pallesen et al., 2010; Slevc, Davey, Buschkuehl, \& Jaeggi, 2016) and show enhanced BOLD responses in the prefrontal 
cortex for N-back difficulty (Pallesen et al., 2010). Finally, music training predicts overall performance on measures of WM updating (i.e., combined performance on spatial $\mathrm{N}$ back, letter memory, and keep track tasks, Okada, 2016), and months of music lessons in children correlate with performance on tasks tapping inhibition, updating, and shifting (Degé, Wehrum, Stark, \& Schwarzer, 2011; but see Schellenberg, 2011).

\section{Randomized Controlled Trials: Musical Training and EF}

There is considerable evidence that music training is associated with advantages in all three domains of EF. However, the studies described above are correlational in nature, and have contrasted musicians and nonmusicians by recruiting participants who had already undergone various amounts and types of music training. Consequently, it is entirely possible that musicians' advantages in EF tasks do not result from training per se, but instead reflect pre-existing differences that lead some people with relatively high EF abilities to pursue music training (cf. Schellenberg, 2015).

Although the possibility of pre-existing differences and selection bias preclude claims of causation from these studies, promising results have still been found while trying to control for these factors. Therefore, these correlational findings are best interpreted as suggesting appropriate avenues to explore in experimental studies that (ideally) randomly assign participants to music training or a well-matched control training regimen. Although the few longitudinal, randomized studies that have been conducted used different tasks that span a wide range of cognitive abilities (e.g., WM, reading ability, and verbal intelligence; Moreno et al., 2011) and employed music training regimens of varying types, duration, and intensity, intriguing results have been found suggesting that taking music lessons may indeed enhance EF performance. The small body of experimental studies of music training and EFs are summarized in Table 1.

In the first training study to specially evaluate EFs, Bugos et al. (2007) randomly assigned 31 older adults (aged 60 to 85 years) to receive individualized piano lessons or to a no-treatment control group. The weekly piano lessons included lessons about music theory, practice with etudes, and songs from a lesson book. After six months of lessons, those who received music training showed improved cognitive functioning on the Trail-Making Test, Part $B$, in which subjects connect dots alternating between sequential numbers and letters in alphabetical order (i.e., A, 1, B, 2, C, 3, etc.). Given that the comparison performance was with a no-treatment control group, these results must be taken with caution (Shadish, Cook, \& Campbell, 2002). Nonetheless, these data still suggest that music lessons may improve performance on nonmusical aspects of cognitive flexibility.

While it is difficult to draw conclusions from studies with a no-treatment control group given the possibility of cognitive "placebo" effects (cf. Boot, Simons, Stothart, \& Stutts, 2013), more definitive conclusions can be drawn when there is a comparable active control group. One such randomized study looked at the effect of a computerized music program on the EF component of inhibitory control. Moreno et al. (2011) assigned four- to six-year-old children to either a computerized music training program, in which they learned about basic musical concepts like pitch and rhythm, or a computerized visual arts training program, in which they learned about concepts like 
shape or color. (Note that, in contrast to most studies investigating transfer from music training, the tasks used by Moreno et al. were all perceptual, and children did not learn how to play an instrument.) After four weeks of daily training, the children who received music training showed greater gains in inhibitory control than the children who received visual arts training, as shown in larger P2 peak amplitudes in no-go trials in a go/no-go task (see Moreno \& Farzan, 2015, for discussion).

Two other studies have focused on the EF component of working memory, albeit using different tasks to measure this construct. Roden, Grube, Bongard, and Kreutz (2014) assigned 7-8-year-old children to either 18 months of weekly music lessons on an instrument of their choosing or a natural science training program. They found that those in the music group performed better on a counting span test and a complex span test (Roden et al., 2014). Somewhat more equivocal evidence comes from Mehr, Schachner, Katz, and Spelke (2013), who randomly assigned 4-year-old children to either music or visual arts training, both of which were designed to cover many content standards in the National Standards for Arts Education and to encourage "parent-child play" (Mehr et al., 2013, Exp. 1). After six weeks of weekly lessons, those who had music lessons performed better on a map use/navigation task, which involves holding a 2-D map with landmarks (i.e., circles that represented barrels from an aerial view) in working memory and manipulating it to navigate a 3-D world (i.e., real barrels in the room). Both tasks necessitate the storing and processing of information, and can be considered tasks tapping working memory ability. However, Mehr et al. (2013) did not find differences on an omnibus test of all four tasks assessed between the music and visual arts group but found this difference only when analyzing data from the two spatial tasks described here. Moreover, in a follow-up study comparing a new group of children randomly assigned to either music lessons or to a no-treatment control, this effect was not found (Mehr et al., 2013, Exp. 2).

Lastly, Schellenberg (2004) reported evidence that music lessons can impact measures of general intelligence, which likely involve multiple aspects of EFs (e.g., reasoning and problem solving). Six-year-old children were randomly assigned to standard keyboard lessons, Kodály voice lessons, drama lessons, or no lessons. After 36 weeks of training, those who received keyboard and voice lessons had greater increases in full-scale IQ than those taking drama lessons or no lessons. There is some debate as to whether these effects on general intelligence reflect underlying EF advantages. In a subsequent correlational study, Schellenberg (2011) found no link between music lessons and most measures of EF assessed (Phonological Fluency, Sun-Moon Stroop, Tower of Hanoi, and Wisconsin Card Sorting Test). However, these tasks may not have recruited EFs given the age group (9-12 year olds, Bialystok, 2011), and other evidence from Degé, Kubicek, and Schwarzer (2011) suggests that EFs do indeed mediate the relation between music lessons and intelligence when using different EF tasks (from the NEPSY-II; Korkman, Kirk, \& Kemp, 2007). Given that these studies use different categorizations of musicians versus nonmusicians, as well as different EF tasks, it remains unclear whether increases in IQ are mediated by improvements of lower-level EFs.

Despite these promising results, other evidence suggests that music lessons may not benefit cognitive processing. As mentioned earlier, results from Mehr et al.'s 
(2013) randomized control experiments were equivocal overall. Furthermore, Rickard, Bambrick, and Gill (2012) found no differences between 10-13-year-old children who took 6.5 months of classroom-based music lessons and children who instead took 6.5 months of drama or art lessons on tests of verbal memory as well as IQ (Rickard et al., 2012). However, these studies examined only classroom-based group music lessons, which may place different demands on EFs than private music lessons.

In sum, the small body of extant randomized control studies on EFs and music training have found somewhat mixed results. Because of the disparity in the EF measures used, EF components studied, and the length, intensity, and type of training administered, it is difficult to compare and draw general conclusions about these results. Additional work is thus clearly needed. Nevertheless, these few studies combined with a larger body of correlational evidence (see above) suggests that music training might indeed show transfer to tasks of EFs. And because EFs are predictive of multiple positive outcomes (e.g., success in school, quality of life, and mental health; see Diamond, 2013), it would be tremendously valuable to know if, and how, musical experiences could function as a kind of EF training. Below, we consider several relevant questions posed by Diamond and Ling's challenge chapter (2017) from the perspective of music training and EFs. It is our hope that these considerations can help guide future research on if and how music training might serve not only as an intrinsically valuable pursuit, but also as an enjoyable "naturalistic" EF training program.

Who benefits most from what? Does the answer differ by age, gender, or cultural group of the participants, or another variable? For example, are different methods for improving EFs more beneficial at different ages?

Given the limited populations investigated in previous randomized studies of music training, it is not yet clear if certain age groups benefit more from music training. All but one of the randomized studies listed in Table 1 looked at young children (age range of 4-7 years) because EFs are thought to be more malleable during childhood and adolescence. However, one study on older adults aged 60 to 85 did find EF improvements after piano lessons as well (albeit without an active control group for comparison; Bugos et al., 2007). There is also correlational evidence that music training may help prevent perceptual cognitive decline in the aging brain (Kraus \& WhiteSchwoch, 2014), which suggests that music training may be beneficial for the older adult population as well. A likely, but so far untested, possibility is that beneficial effects of musical experience will be more pronounced in populations with relatively lower EF abilities, such as children, elderly adults, or neuropsychological patients, as has been found regarding "bilingual advantages" in inhibitory control (cf. Bialystok, Craik, \& Luk, 2012).

Differences related to gender and culture are yet unknown: no study examining music training has reported differential EF benefits by gender, and all studies to date of EF and music training teach music grounded in the Western tonal system. Presumably, different cultures would benefit more from training in their own musical system, but it is not necessarily the case that different musical systems place the same demands on EFs. 
If a real-life activity improves EFs (be it theater, martial arts, soccer, a school curriculum, or something else), what aspect(s) of the program are responsible for that? Why did the program improve EFs?

As stated above, future studies should begin to investigate the effect of different aspects of music training (e.g., sight-reading and ensemble playing) on EFs. By using well-controlled, randomized studies to examine various components of music training, we will be able to determine which components are responsible for improving EFs. Thus, we will have a better understanding of how music training, as a whole, taxes and affects EFs.

While it is of utmost importance to perform well-controlled longitudinal studies in the lab (to determine causal relations), it is equally vital to perform quasi-experimental or observational studies of music training in the field. Even though these types of studies will suffer from selection bias, it is still important to understand the types of people who choose to study music and how this training affects them. Specifically, these more "naturalistic" music training programs should also produce insights into the effects of real-life music training on EFs. Furthermore, because taking music lessons is associated not only with cognitive benefits, but also with various social effects (e.g., music lessons are associated with increased quality of school life [Eerola \& Eerola, 2014] and joint music making leads to prosocial behavior [Kirschner \& Tomasello, 2010]), examination of a range of noncognitive abilities affected by music training is also needed.

\section{What makes the best control condition?}

As has been discussed in other domains of training and transfer (e.g., video games: Boot et al., 2013), a proper control condition needs to be equally engaging as music training (i.e., a convincing placebo control). Additionally, if the control condition does not account for all differential expectations, it will confound the experiment, and no causal claims can be made about the music training group (Boot et al., 2013). Therefore, a proper control condition should also incorporate as many nonmusical aspects of the music training program as possible (e.g., motor training, engaging lessons, self-efficacy, any social aspects, etc.) so that any differences in the outcome variables can be attributed solely to the music lessons. (Of course, potential EF benefits from these other aspects of music training are also worthy of investigation, even if not specific to the musical aspect of training.) Early work on music training did not use active control groups and so offers only suggestive evidence that music training enhances aspects of cognitive ability in children (Bilhartz et al., 2000; Costa-Giomi, 1999; 2004) and older adults (Bugos et al., 2007). However, more recent studies have used drama lessons, natural science lessons, and visual arts lessons for active control groups (Schellenberg, 2006; Roden et al., 2014 Moreno et al., 2011; Mehr et al., 2013), and, in an ongoing large longitudinal study, sports training (Habibi et al., 2014; Habibi, Cahn, Damasio, \& Damasio, 2016). The variety in these training programs is advantageous as they are likely to be effective controls for different nonmusical aspects of music training. 
What are the best doses, frequencies, and durations for different programs intended to improve EFs? Does the answer differ by type of program, EF component (e.g., WM or response inhibition), the age, gender, or cultural group of the participants, or any other variable? For example, does the optimal dose or frequency differ by age?

Because of the shortage of longitudinal, randomized studies with music training programs, there is a lack of converging evidence for effects of different types of music training on each of the three EF components. Furthermore, the length and duration of training regimens greatly differs in the few randomized studies that have been conducted (see Table 1). Extant studies have used training programs ranging from only 4.5 hours over six weeks (Mehr et al., 2013) to 45 minutes weekly over 1.5 years (Roden et al., 2014). Improved performance on a switching task was found after six months of lessons (Bugos et al. 2007), and increased performance on an inhibition task was found after only 28 days of more intense daily training (Moreno et al., 2011). Furthermore, effects such as increased full-scale IQ have been seen in musicians after as little as a total of 28 hours (over 36 weeks) of music lessons (Schellenberg, 2004). However, Mehr et al. (2013) failed to find any effects on tasks of receptive vocabulary, numerical quantity discrimination, and spatial reasoning after 4.5 hours of lessons over six weeks (see Table 1 for summary), which suggests that music training programs may need to exceed this low dosage to see transfer effects.

Taken together, these findings suggest that training studies should employ at least 13 hours of lessons (as in Bugos et al., 2007) and should ideally allow for practice daily (Moreno et al., 2011) or weekly (Bugos et al., 2007). Because many correlations have been found between cognitive processes and real-world music lessons, which typically occur once a week, and because it is important to maximize the external validity of these studies, it seems reasonable to recommend that a music training program should administer lessons at least once per week.

What factors affect how long benefits last? Does it matter which method is used to try to sustain benefits (e.g., booster sessions or embed in daily activities)? If refresher or booster sessions are used, at what intervals should they be given and for what duration? Do the answers to these questions differ by type of program, EF component (e.g., WM or response inhibition), the age, gender, or cultural group of the participants, or other variables?

Unfortunately, very little evidence exists regarding the degree to which musicallyinduced EF benefits persist (Costa-Giomi, 2014). To our knowledge, the only longitudinal music training study using delayed testing was Bugos et al. (2007), who found that only improvements on the digit symbol task, a test of processing speed, remained three months after training had stopped (without a booster session). However, improvements on other tasks improved by training (specifically, the Trail-Making Test, an EF task) did not persist after the three-month delay. Other evidence from a correlational study showed that adults who had taken music lessons during childhood had more robust brain stem responses to speech in noise than adults who had not taken music lessons as children (Skoe \& Kraus, 2012), suggesting that neural changes 
may persist for several years after music training has been discontinued. However, more work is clearly necessary to examine the longevity of these effects.

What about training people in strategies to minimize the need for EFs, so that people do not have to expend so much effort trying to exercise EFs?

Although previous work has not explicitly investigated this topic, evidence that music training leads to improvements in EF task performance could also be interpreted as music training minimizing the need for EFs in those tasks. For example, developing skill in reading and playing music may allow musicians to do these tasks with less cognitive effort (e.g., via expertise-dependent strategies for storing and processing musical material; e.g., Barry \& Hallam, 2003; Chaffin \& Imreh, 1997; 2002; Nielsen, 2001), which is interesting from the perspective of musical skill acquisition. In addition, this raises the possibility that developing strategies that minimize reliance on EFs in musical contexts might transfer to some other sorts of EF-demanding tasks, which would be a quite different explanation for transfer from the EF-enhancement account discussed here.

\section{Will the type of program end up mattering more or the way it is done?}

The type of program and the way it is enacted are likely equally important. To see benefits, any training program should be done in a way that constantly taxes and strengthens EFs and continues to increase in difficulty (Diamond, 2013). In terms of a music training program, then, music lessons should incorporate skills that build upon one another, with gradual increases in complexity (Bugos et al., 2007). In addition, one presumed advantage of music training interventions is the intrinsic value of musical experiences. That is, people engage in playing instruments or singing because it is an enjoyable activity. For this reason, it is important that music training programs teach self-efficacy and motivate participants to practice (Bugos et al., 2007).

If we expect to see near-transfer from music lessons to specific components of $E F$, then a music training program should be one that contains lessons that tax each specific underlying component of EF. For example, to produce transfer from music training to working memory updating, music lessons might usefully include practice reading music and sight-reading. As discussed above, these processes require one to visually scan ahead in the musical score (Goolsby, 1994) and hold the representations of these notes in mind while simultaneously updating the notes that have already been and are yet to be played. If, indeed, practice reading music and sight-reading can strengthen working memory updating, one should expect to see transfer effects to tasks of working memory updating.

Similarly, to investigate transfer effects to cognitive flexibility, a music training program might include practice playing in an ensemble, which may tap cognitive flexibility (e.g., Loehr \& Palmer, 2011; Moore \& Chen, 2010). Lastly, a music training program targeting inhibitory control might usefully include practice with complex polyrhythms (e.g., Vuust et al., 2006; 2011). 


\section{Conclusion}

Because many aspects of music training (e.g., reading music, practicing, playing in ensembles) are likely to engage EFs, and because many people enjoy music lessons solely for their intrinsic value, music training can be considered a relatively easy to implement "naturalistic" EF training program. Given the pervasive role of EFs that may underlie learning to play an instrument, future research should consider the many different types of processes engaged in music training programs as well as the various EF components each process might affect. To use music training as a "naturalistic" EF training program, we must first understand which specific aspects of music lessons are causing the benefits in specific components of EF. Fortunately, there is growing interest in the cognitive underpinnings of musical tasks and in the potential for nonmusical effects of music training. This blossoming area of research will likely paint a clearer picture of the exact associations between music training and EFs. 


\section{References}

Andersson, P. K., Kristensson, P., Wästlund, E., \& Gustafsson, A. (2012). Let the music play or not: The influence of background music on consumer behavior. Journal of Retailing and Consumer Services, 19(6), 553-560.

Au, J., Sheehan, E., Tsai, N., Duncan, G. J., Buschkuehl, M., \& Jaeggi, S. M. (2015). Improving fluid intelligence with training on working memory: A metaanalysis. Psychonomic Bulletin \& Review, 22(2), 366-377.

Bialystok, E. (2011). Commentary: How does experience change cognition? Evaluating the evidence. British Journal of Psychology, 102, 303-305.

Bialystok, E., Craik, F. I. M., \& Luk, G. (2012). Bilingualism: Consequences for mind and brain. Trends in Cognitive Sciences, 16(4), 240-250.

Bialystok, E., \& Depape, A.-M. (2009). Musical expertise, bilingualism, and executive functioning. Journal of Experimental Psychology: Human Perception and Performance, 35(2), 565-574.

Bilhartz, T. D., Bruhn, R. A., \& Olson, J. E. (2000). The effect of early music training on child cognitive development. Journal of Applied Developmental Psychology, 20(4), 615-636.

Boot, W. R., Simons, D. J., Stothart, C., \& Stutts, C. (2013). The pervasive problem with placebos in psychology: Why active control groups are not sufficient to rule out placebo effects. Perspectives on Psychological Science, 8(4), 445-454.

Botvinick, M. M., Braver, T. S., Barch, D. M., Carter, C. S., \& Cohen, J. D. (2001). Conflict monitoring and cognitive control. Psychological Review, 108(3), 624-652.

Bugos, J. A., Perlstein, W. M., McCrae, C. S., Brophy, T. S., \& Bedenbaugh, P. H. (2007). Individualized piano instruction enhances executive functioning and working memory in older adults. Aging \& Mental Health, 11(4), 464-471.

Bugos, J., \& Mostafa, W. (2011). Musical training enhances information processing speed. Bulletin of the Council for Research in Music Education, 187, 7-18.

Burton-Hill, A. (2012, June 14). José Antonio Abreu on Venezuela's El Sistema miracle. The Guardian. http://www.theguardian.com/music/2012/jun/14/abreu-el-sistema-venezuela-interview-clemencyburton-hill.

Butzlaff, R. (2000). Can music be used to teach reading? Journal of Aesthetic Education, 34(3-4), 167178.

Chan, A. S., Ho, Y. C., \& Cheung, M. C. (1998). Music training improves verbal memory. Nature, 396(6707), 128.

Chein, J. M., \& Morrison, A. B. (2010). Expanding the mind's workspace: Training and transfer effects with a complex working memory span task. Psychonomic Bulletin \& Review, 17(2), 193-199.

Costa-Giomi, E. (1999). The effects of three years of piano instruction on children's cognitive development. Journal of Research in Music Education, 47(3), 198-212.

Costa-Giomi, E. (2004). Effects of three years of piano instruction on children's academic achievement, school performance and self-esteem. Psychology of Music, 32(2), 139-152.

Costa-Giomi, E. (2014). The long-term effects of childhood music instruction on intelligence and general cognitive abilities. Update: Applications of Research in Music Education, 33(2), 20-26.

Degé, F., Kubicek, C., \& Schwarzer, G. (2011). Music lessons and intelligence: A relation mediated by executive functions. Music Perception, 29(2), 195-201.

Degé, F., Wehrum, S., Stark, R., \& Schwarzer, G. (2011). The influence of two years of school music training in secondary school on visual and auditory memory. European Journal of Developmental Psychology, 8(5), 608-623.

Diamond, A. (2013). Executive functions. Annual Review of Psychology, 64(1), 135-168.

Diamond, A., Barnett, W. S., Thomas, J., \& Munro, S. (2007). Preschool program improves cognitive control. Science, 318(5855), 1387-1388.

Diamond, A., \& Ling, D. (2017). Review of the evidence on fundamental questions surrounding and efforts to improve executive functions (including working memory). in M. Bunting, J. Novick, M. Dougherty, \& R. W. Engle (Eds.), An integrative approach to cognitive and working memory training: Perspectives from psychology, neuroscience, and human development. New York: Oxford University Press. 
Dougherty, M. R., Hamovitz, T., \& Tidwell, J. W. (2015). Reevaluating the effectiveness of n-back training on transfer through the Bayesian lens: Support for the null. Psychonomic Bulletin \& Review, 22(3), 1-11.

Drake, C., \& Palmer, C. (2000). Skill acquisition in music performance: relations between planning and temporal control. Cognition, 74(1), 1-32.

Eerola, P.-S., \& Eerola, T. (2014). Extended music education enhances the quality of school life. Music Education Research, 16(1), 88-104.

Furneaux, S., \& Land, M. F. (1999). The effects of skill on the eye-hand span during musical sightreading. Proceedings of the Royal Society B: Biological Sciences, 266(1436), 2435-2440.

Gaser, C., \& Schlaug, G. (2003). Brain structures differ between musicians and non-musicians. The Journal of Neuroscience, 23(27), 9240-9245.

Goolsby, T. W. (1994). Eye movement in music reading: Effects of reading ability, notational complexity, and encounters. Music Perception, 12(1), 77-96.

Habibi, A., Cahn, B. R., Damasio, A., \& Damasio, H. (2016). Neural correlates of accelerated auditory processing in children engaged in music training. Developmental Cognitive Neuroscience, 21, 114.

Habibi, A., Ilari, B., Crimi, K., Metke, M., Kaplan, J. T., Joshi, A. A., . . Damasio, H. (2014). An equal start: Absence of group differences in cognitive, social, and neural measures prior to music or sports training in children. Frontiers in Human Neuroscience, 8:690.

Hanna-Pladdy, B., \& MacKay, A. (2011). The relation between instrumental musical activity and cognitive aging. Neuropsychology, 25(3), 378-386.

Hannon, E. E., \& Trainor, L. J. (2007). Music acquisition: Effects of enculturation and formal training on development. Trends in Cognitive Sciences, 11(11), 466-472.

Harrison, T. L., Shipstead, Z., Hicks, K. L., Hambrick, D. Z., Redick, T. S., \& Engle, R. W. (2013). Working memory training may increase working memory capacity but not fluid intelligence. Psychological Science, 24(12), 2409-2419.

Ho, Y.-C., Cheung, M.-C., \& Chan, A. S. (2003). Music training improves verbal but not visual memory: Cross-sectional and longitudinal explorations in children. Neuropsychology, 17(3), 439-450.

Hudziak, J. J., Albaugh, M. D., Ducharme, S., Karama, S., Spottswood, M., Crehan, E., . . Botteron, K. N. (2014). Cortical thickness maturation and duration of music training: Health-promoting activities shape brain development. Journal of the American Academy of Child \& Adolescent Psychiatry, 53(11), 1153-1161.

Hyde, K. L., Lerch, J., Norton, A., Forgeard, M., Winner, E., Evans, A. C., \& Schlaug, G. (2009). Musical training shapes structural brain development. The Journal of Neuroscience, 29(10), 3019-3025.

Jaeggi, S. M., Buschkuehl, M., Jonides, J., \& Perrig, W. J. (2008). Improving fluid intelligence with training on working memory. Proceedings of the National Academy of Sciences of the United States of America, 105(19), 6829-6833.

Jakobson, L. S., Cuddy, L. L., \& Kilgour, A. R. (2003). Time tagging: A key to musicians' superior memory. Music Perception, 20(3), 307-313.

Jakobson, L. S., Lewycky, S. T., Kilgour, A. R., \& Stoesz, B. M. (2008). Memory for verbal and visual material in highly trained musicians. Music Perception, 26(1), 41-55.

Jentzsch, I., Mkrtchian, A., \& Kansal, N. (2014). Improved effectiveness of performance monitoring in amateur instrumental musicians. Neuropsychologia, 52(100), 117-124.

Karageorghis, C. I. \& Priest, D.-L. (2012). Music in the exercise domain: a review and synthesis (part I). International Review of Sport and Exercise Psychology, 5(1), 44-66.

Kirschner, S. \& Tomasello, M. (2010). Joint music making promotes prosocial behavior in 4-year-old children. Evolution and Human Behavior, 31(5), 354-364.

Korkman, M., Kirk, J., \& Kemp, S. (2007). A developmental neuropsychological assessment; NEPSY-II (2nd ed.). San Antonio, TX: Harcourt Assessment, Inc.

Kraus, N., \& White-Schwoch, T. (2014). Music training: Lifelong investment to protect the brain from aging and hearing loss. Acoustics Australia, 42(2), 117-123.

Lamb, S. J., \& Gregory, A. H. (1993). The relationship between music and reading in beginning readers. Educational Psychology, 13(1), 19-27.

Lehto, J. E., Juujärvi, P., Kooistra, L., \& Pulkkinen, L. (2003). Dimensions of executive functioning: Evidence from children. British Journal of Developmental Psychology, 21(1), 59-80. 
Loehr, J. D., Kourtis, D., Vesper, C., Sebanz, N., \& Knoblich, G. (2013). Monitoring individual and joint action outcomes in duet music performance. Journal of Cognitive Neuroscience, 25(7), 10491061.

Loehr, J. D., \& Palmer, C. (2011). Temporal coordination between performing musicians. The Quarterly Journal of Experimental Psychology, 64(11), 2153-2167.

Logue, S. F., \& Gould, T. J. (2014). The neural and genetic basis of executive function: attention, cognitive flexibility, and response inhibition. Pharmacology Biochemistry and Behavior, 123, 4554 .

Mehr, S. A., Schachner, A., Katz, R. C., \& Spelke, E. S. (2013). Two randomized trials provide no consistent evidence for nonmusical cognitive benefits of brief preschool music enrichment. PLoS ONE, 8(12), e82007.

Meinz, E. J., \& Hambrick, D. Z. (2010). Deliberate practice is necessary but not sufficient to explain individual differences in piano sight-reading skill: The role of working memory capacity. Psychological Science, 21(7), 914-919.

Milliman, R. E. (1982). Using background music to affect the behavior of supermarket shoppers. Journal of Marketing, 46(3), 86-91.

Miyake, A., Friedman, N. P., Emerson, M. J., Witzki, A. H., Howerter, A., \& Wager, T. D. (2000). The unity and diversity of executive functions and their contributions to complex "Frontal Lobe" tasks: A latent variable analysis. Cognitive Psychology, 41(1), 49-100.

Miyake, A., \& Friedman, N. P. (2012). The nature and organization of individual differences in executive functions: Four general conclusions. Current Directions in Psychological Science, 21(1), 8-14.

Moore, G. P., \& Chen, J. (2010). Timings and interactions of skilled musicians. Biological Cybernetics, 103(5), 401-414.

Moradzadeh, L., Blumenthal, G., \& Wiseheart, M. (2015). Musical training, bilingualism, and executive function: A closer look at task switching and dual-task performance. Cognitive Science, 39(5), 992-1020.

Moreno, S., Bialystok, E., Barac, R., Schellenberg, E. G., Cepeda, N. J., \& Chau, T. (2011). Short-term music training enhances verbal intelligence and executive function. Psychological Science, 22(11), 1425-1433.

Moreno, S., \& Farzan F. (2015). Music training and inhibitory control: A multidimensional model. Annals of the New York Academy of Sciences, 1337(1), 147-152.

Moreno, S., Wodniecka, Z., Tays, W., Alain, C., \& Bialystok, E. (2014). Inhibitory control in bilinguals and musicians: Event related potential (ERP) evidence for experience-specific effects. PLoS ONE, 9(4), e94169.

Nachev, P., Kennard, C., \& Husain, M. (2008). Functional role of the supplementary and presupplementary motor areas. Nature Reviews: Neuroscience, 9(11), 856-869.

Nee, D. E., Brown, J. W., Askren, M. K., Berman, M. G., Demiralp, E., Krawitz, A., \& Jonides, J. (2013). A meta-analysis of executive components of working memory. Cerebral Cortex, 23(2), 264-282.

Oechslin, M. S., Van De Ville, D., Lazeyras, F., Hauert, C. A., \& James, C. E. (2013). Degree of musical expertise modulates higher order brain functioning. Cerebral Cortex, 23(9), 2213-2224.

Okada, B. M. (2016). Musical Training and Executive Functions. (Master's Thesis). Available from Digital Repository at the University of Maryland. URI: http://hdl.handle.net/1903/18933.

Owen, A. M., Hampshire, A., Grahn, J. A., Stenton, R., Dajani, S., Burns, A. S., . . Ballard, C. G. (2010). Putting brain training to the test. Nature, 465(7299), 775-778.

Pallesen, K. J., Brattico, E., Bailey, C. J., Korvenoja, A., Koivisto, J., Gjedde, A., \& Carlson, S. (2010). Cognitive control in auditory working memory is enhanced in musicians. PLoS ONE, 5(6), e11120.

Palmer, C. (2013). Music performance: Movement and coordination. In D. Deutsch (Ed.), The psychology of music (3rd ed.) (pp. 405-422). San Diego, CA: Academic Press

Peretz, I., \& Zatorre, R. J. (2005). Brain organization for music processing. Annual Review of Psychology, $56,89-114$.

Pietschnig, J., Voracek, M., \& Formann, A. K. (2010). Mozart effect-Shmozart effect: A meta-analysis. Intelligence, 38(3), 314-323.

Redick, T. S., Shipstead, Z., Harrison, T. L., Hicks, K. L., Fried, D. E., Hambrick, D. Z., ... \& Engle, R. W. (2013). No evidence of intelligence improvement after working memory training: A randomized, placebo-controlled study. Journal of Experimental Psychology: General, 142(2), 359-379. 
Rickard, N. S., Bambrick, C. J., \& Gill, A. (2012). Absence of widespread psychosocial and cognitive effects of school-based music instruction in 10-13-year-old students. International Journal of Music Education, 30(1), 57-78.

Roden, I., Grube, D., Bongard, S., \& Kreutz, G. (2014). Does music training enhance working memory performance? Findings from a quasi-experimental longitudinal study. Psychology of Music, 42(2), 284-298.

Sala, G., \& Gobet, F. (2017). When the music's over. Does music skill transfer to children's and young adolescents' cognitive and academic skills? A meta-analysis. Educational Research Review, 20, 55-67.

Schellenberg, E. G. (2004). Music lessons enhance IQ. Psychological Science, 15(8), 511-514.

Schellenberg, E. G. (2006). Long-term positive associations between music lessons and IQ. Journal of Educational Psychology, 98(2), 457-468.

Schellenberg, E. G. (2011). Examining the association between music lessons and intelligence. British Journal of Psychology, 102(3), 283-302.

Schellenberg, E. G. (2015). Music training and speech perception: A gene-environment interaction. Annals of the New York Academy of Sciences, 1337(1), 170-177.

Schellenberg, E. G., \& Moreno, S. (2009). Music lessons, pitch processing, and g. Psychology of Music, 38(2) 209-221.

Schellenberg, G., \& Winner, E. (Eds.) (2011). Music training and nonmusical abilities: Introduction. Music Perception, 29(2), 129-132.

Shadish, W. R., Cook, T. D., \& Campbell, D. T. (2002). Experimental and quasi-experimental designs for generalized causal inference. Boston: Houghton Mifflin Company.

Shih, Y. N., Huang, R. H., \& Chiang, H. Y. (2012). Background music: Effects on attention performance. Work, 42(4), 573-578.

Skoe, E., \& Kraus, N. (2012). A little goes a long way: How the adult brain is shaped by musical training in childhood. Journal of Neuroscience, 32(34), 11507-11510.

Slevc, L. R., Davey, N. S., Buschkuehl, M., \& Jaeggi, S. M. (2016). Tuning the mind: Exploring the connections between musical ability and executive functions. Cognition, 152, 199-211.

Slevc, L. R., \& Okada, B. M. (2015). Processing structure in language and music: A case for shared reliance on cognitive control. Psychonomic Bulletin \& Review.

Slevc, L. R., \& Okada, B. M. (2014). Nonmusical abilities. In W. Thompson (Ed.), Music in the social and behavioral sciences: An encyclopedia, vol. 12 (pp. 815-817). Thousand Oaks, CA: SAGE Publications, Inc.

Strait, D., \& Kraus, N. (2011). Playing music for a smarter ear: Cognitive, perceptual and neurobiological evidence. Music Perception, 29(2), 133-146.

Strait, D. L., Kraus, N., Parbery-Clark, A., \& Ashley, R. (2010). Musical experience shapes top-down auditory mechanisms: Evidence from masking and auditory attention performance. Hearing Research, 261, 22-29.

Thompson, W. F., Schellenberg, E. G., \& Husain, G. (2001). Arousal, mood, and the Mozart effect. Psychological Science, 12(3), 248-251.

Vaughn, K. (2000). Music and mathematics: Modest support for the oft-claimed relationship. Journal of Aesthetic Education, 34(3-4), 149-166.

Vuust, P., Roepstorff, A., Wallentin, M., Mouridsen, K., \& Østergaard, L. (2006). It don't mean a thing... Keeping the rhythm during polyrhythmic tension, activates language areas (BA47). Neurolmage, 31(2), 832-841.

Vuust, P., Wallentin, M., Mouridsen, K., Østergaard, L., \& Roepstorff, A. (2011). Tapping polyrhythms in music activates language areas. Neuroscience Letters, 494(3), 211-216.

Zuk, J., Benjamin, C., Kenyon, A., \& Gaab, N. (2014). Behavioral and neural correlates of executive functioning in musicians and non-musicians. PLOS ONE, 9(6), 1-14. 


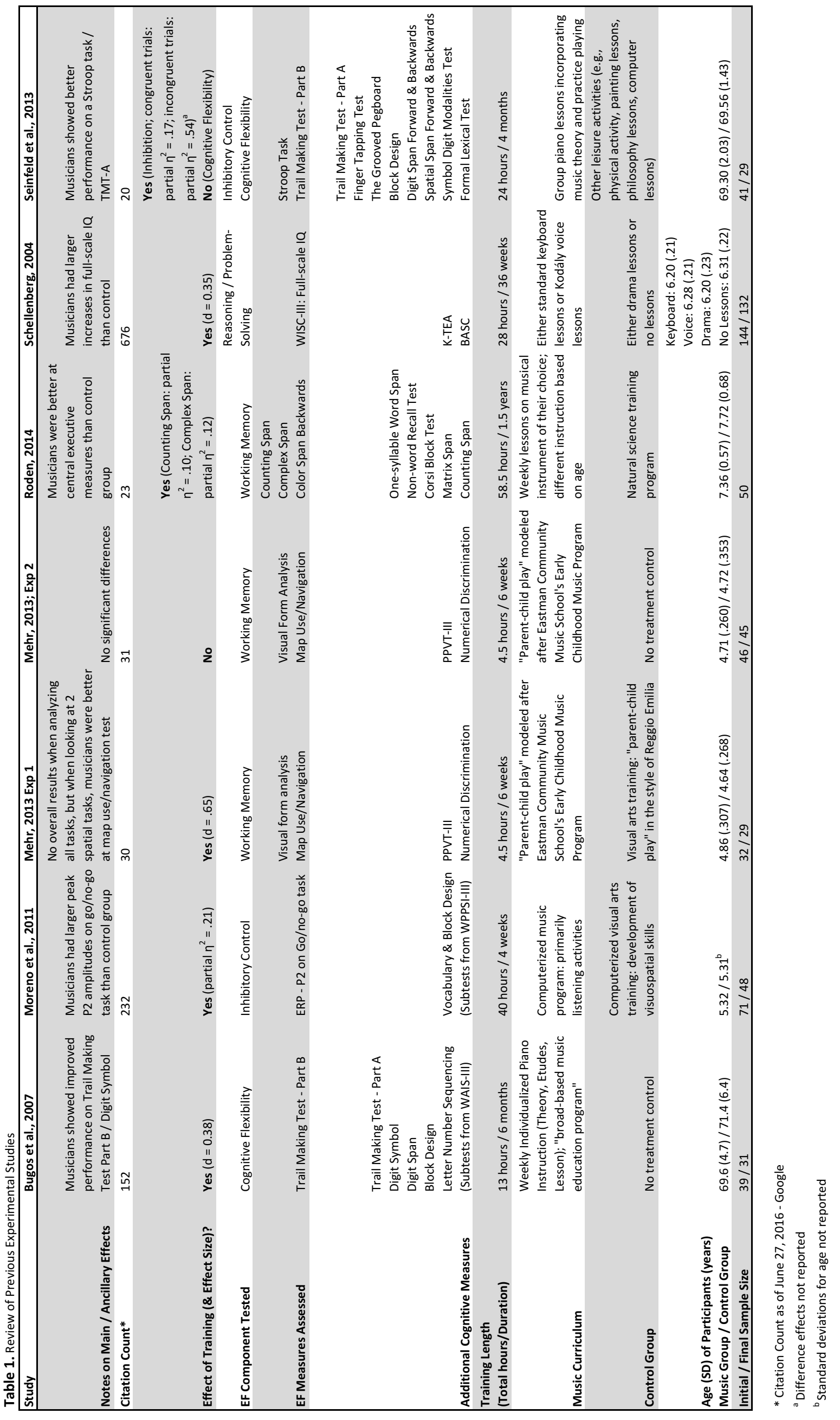

